\title{
Effects of maternal acrolein exposure during pregnancy on testicular testosterone production in fetal rats
}

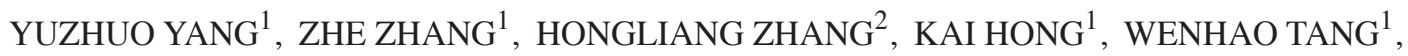 \\ LIANMING ZHAO ${ }^{1}$, HAOCHENG LIN $^{1}$, DEFENG LIU ${ }^{2}$, JIAMING MAO $^{2}$, HAN WU $^{1}$ and HUI JIANG ${ }^{1}$ \\ ${ }^{1}$ Department of Urology and ${ }^{2}$ Reproductive Medicine Center, Peking University Third Hospital, Beijing 100191, P.R. China
}

Received November 24, 2015; Accepted November 29, 2016

DOI: $10.3892 / \mathrm{mmr} .2017 .6624$

\begin{abstract}
Acrolein has been reported to have diverse toxic effects on various organs, including the reproductive system. However, little is known regarding the effects of maternal acrolein exposure on testicular steroidogenesis in male offspring. The present study investigated the effects of acrolein on fetal testosterone production and associated genes. Pregnant Sprague-Dawley rats were intraperitoneally injected with vehicle (normal saline) or 1,2 or $5 \mathrm{mg} / \mathrm{kg}$ acrolein from gestational day (GD) 14-20, and fetal testes were examined on GD 21 . Fetal body and testicular weights were markedly reduced in pups following exposure to high doses of acrolein $(5 \mathrm{mg} / \mathrm{kg})$ in late pregnancy. Notably, in utero exposure of $5 \mathrm{mg} / \mathrm{kg}$ acrolein significantly decreased the testicular testosterone level and downregulated the expression levels of steroidogenic acute regulatory protein (StAR) and $3 \beta$-hydroxysteroid dehydrogenase ( $3 \beta-\mathrm{HSD})$, whereas the levels of other steroidogenic enzymes, including scavenger receptor class B, cholesterol side-chain cleavage enzyme and steroid 17 alpha-hydroxylase/17,20 lyase, were unaffected. Furthermore, the $3 \beta$-HSD immunoreactive area in the interstitial region of the fetal testes was reduced at a $5 \mathrm{mg} / \mathrm{kg}$ dose, whereas the protein expression levels of 4-hydroxynonenalwere dose-dependently increased following maternal exposure to acrolein. mRNA expression levels of insulin-like factor 3, a critical gene involved in testicular descent, were unaltered following maternal acrolein exposure. Taken together, the results of the present study suggested that maternal exposure to high doses of acrolein inhibited fetal testosterone synthesis, and abnormal expression of StAR and $3 \beta$-HSD may be associated with impairment of the steroidogenic capacity.
\end{abstract}

Correspondence to: Dr Hui Jiang, Department of Urology, Peking University Third Hospital, 49 North Garden Road, Haidian, Beijing 100191, P.R. China

E-mail: jianghui55@163.com

Key words: acrolein, fetal Leydig cell, maternal exposure, testosterone, steroidogenesis

\section{Introduction}

Cryptorchidism and hypospadias in newborn males, and infertility and testicular germ cell cancer in adult males, are common male reproductive system disorders worldwide $(1,2)$. These disorders have been hypothesized to be associated with testicular dysgenesis syndrome (TDS), which originates in male fetal life (3). An important factor contributing to TDS is androgen dysfunction during the masculinization programming window. Masculinization is a pivotal event during reproductive tract development, driven by androgen produced by the fetal testes (4). Specific factors influencing this process, including exposure to certain environmental pollutants, may cause inadequate production of androgen, and ultimately lead to abnormal reproductive development (5-7).

Acrolein, a cyclophosphamide metabolite, is a common environmental and dietary pollutant arising from the combustion of fuels, plastic and fried food, and is additionally a primary component of tobacco (8). Acrolein may be generated endogenously during cellular metabolism by lipid peroxidation and degradation of threonine and polyamines. It has been identified as one of the most harmful non-biological air pollutants in residences in the United States $(9,10)$. Increased acrolein exposure has been reported to be associated with various diseases, including diabetes mellitus, hepatotoxicity, cardiovascular disease and Alzheimer's disease (11-13).

Acrolein has been demonstrated to induce embryo lethality and teratogenicity in cultured rat embryos, and causes reproductive toxicity in a yeast gametogenesis model $(14,15)$. Cyclophosphamide (CP), the precursor of acrolein, is used as a therapeutic agent for the treatment of childhood cancers; however, it may be associated with a high risk of infertility and long-term gonadal toxicity in male survivors (16). Additionally, cytochrome P450 3A 4 and 5, the two key enzymes that metabolize $\mathrm{CP}$ into acrolein, are highly expressed in mammalian testes, which may lead to an increased concentration of acrolein in the testes of patients treated with CP $(17,18)$. As acrolein efficiently reaches the testes, it may interfere with steroidogenesis during fetal development, when testosterone production by Leydig cells is critical for normal sexual development. However, little is known regarding the effects of acrolein exposure in maternal rats on the steroidogenic function and sexual development of male offspring. The present study aimed to investigate the dose-dependent effects of 
acrolein on prenatal testosterone production, and the expression levels of the factors involved in testosterone biosynthesis in the fetal rat testes.

\section{Materials and methods}

Ethical approval. The present study was performed in compliance with the regulations of the Medical Ethics Committee of Peking University Third Hospital (Beijing, China; ethical approval no. LA2015205).

Chemicals and reagents. Acrolein (10 mg/ml; CAS107-02-8) was purchased from AccuStandard, Inc. (New Haven, CT, USA). Anti-3 $\beta$-hydroxysteroid dehydrogenase ( $3 \beta$-HSD; catalog no. ab150384), anti-steroidogenic acute regulatory protein (StAR; catalog no. ab203193), anti-4-hydroxynonenal (4-HNE; catalog no. ab46545) and anti-glyceraldehyde-3-phosphate dehydrogenase (GAPDH; catalog no. ab181602) rabbit primary antibodies were obtained from Abcam (Cambridge, MA, USA). All other reagents were purchased from Sigma-Aldrich; Merck Millipore (Darmstadt, Germany) or as otherwise specified.

Animals and treatments. Pregnant Sprague-Dawley rats $(n=32$, with $n=8$ used for preliminary studies and 24 for formal studies; Vital River Laboratories, Co., Ltd., Beijing, China) were individually housed and maintained under a 12-h light/dark cycle at a controlled temperature $\left(20-25^{\circ} \mathrm{C}\right)$ and humidity $(50 \pm 5 \%)$ for one week prior to the experiments. The study was performed according to the Guide for the Care and Use of Laboratory Animals published by the National Institutes of Health (Bethesda, MD, USA). Acrolein was administered intraperitoneally (i.p.), in accordance with previous studies of maternal exposure (19). Our preliminary study revealed that rats died 4 days following injection of $10 \mathrm{mg} / \mathrm{kg}$ acrolein, and as testosterone levels in the fetal testes decreased significantly in the $5 \mathrm{mg} / \mathrm{kg}$ group, a dose of $5 \mathrm{mg} / \mathrm{kg}$ was used in the present study. A total of 24 pregnant rats at gestational days (GD) 14-20 were divided into four groups $(n=6)$ and injected i.p. with 1,2 or $5 \mathrm{mg} / \mathrm{kg}$ acrolein, with an equal volume of saline serving as the control according to previous studies $(20,21)$. Pregnant rats were anesthetized with an i.p. injection of $50 \mathrm{mg} / \mathrm{kg}$ sodium pentobarbital (Sinopharm Chemical Reagent, Co., Ltd., Beijing, China) at GD 21. The fetal rats were harvested by cesarean section, weighed and dissected under a stereomicroscope. Gender was determined by morphology and the gonads. All male fetuses were sacrificed by decapitation and whole blood was collected in a tube with heparin for testosterone analysis. Fetal testes were aseptically removed and stored at $-80^{\circ} \mathrm{C}$ for analysis of testosterone levels, reverse transcription-quantitative polymerase chain reaction (RT-qPCR) and histology.

$R T-q P C R$. Total RNA was extracted using TRIzol ${ }^{\circledR}$ reagent (Invitrogen; Thermo Fisher Scientific, Inc., Waltham, MA, USA). The quantity and quality of the purified RNA was evaluated by spectroscopy. cDNA was synthesized using a RevertAid First Strand cDNA Synthesis Kit (catalog no. K1621; Thermo Fisher Scientific, Inc.), according to the manufacturer's protocol. qPCR was performed using the SYBR ${ }^{\circledR}$ Green Master mix (Fermentas; Thermo Fisher Scientific, Inc.) and the Applied Biosystems 7500 Real-Time PCR system (Applied Biosystems; Thermo Fisher Scientific, Inc.). The cycling conditions were as follows: 1 cycle at $95^{\circ} \mathrm{C}$ for $5 \mathrm{~min}$, and 40 cycles of amplification at $95^{\circ} \mathrm{C}$ for $15 \mathrm{sec}$ and $60^{\circ} \mathrm{C}$ for $1 \mathrm{~min}$. All the samples were run in duplicate using the threshold suggested by the software for the instrument to calculate the quantitation cycle $(\mathrm{Cq})$. Following RT-qPCR, a melting curve analysis was performed to demonstrate the specificity of the PCR products, which revealed that the melting curve for the PCR product of each gene transcript had a single peak (data not shown). To normalize the readings, $\mathrm{Cq}$ values from GAPDH served as internal controls for each run, obtaining a $\triangle \mathrm{Cq}$ value for each gene. Relative alterations in the gene expression data were analyzed using the $2^{-\Delta \Delta \mathrm{Cq}}$ method (22). Primer sequences are presented in Table I.

Western blot analysis. Fetal testes were washed twice with ice-cold phosphate buffered saline (PBS) and homogenized with RIPA lysis buffer containing protease inhibitors (Beijing Solarbio Science \& Technology Co., Ltd., Beijing, China). The protein concentration was quantified using the Bicinchoninic Acid Protein assay kit (Beijing CoWin Biotech, Co., Ltd., Beijing, China). Proteins $(30 \mu \mathrm{g})$ in lysates were separated by $10 \%$ SDS-PAGE, transferred to nitrocellulose membranes (Applygen Technologies, Inc., Beijing, China), and blocked with $5 \%$ bovine serum albumin (BSA; Sigma-Aldrich; Merck Millipore) at room temperature for $1 \mathrm{~h}$. Membranes were subsequently incubated at $4^{\circ} \mathrm{C}$ overnight with the following rabbit primary antibodies, all at a 1:1,000 dilution: Anti-StAR, anti-4-HNE or anti-GAPDH, following which corresponding IRDye-conjugated goat anti-rabbit IgG secondary fluorescent antibodies (cat. no. 925-32211; 1:10,000 dilution; LI-COR Biosciences, Lincoln, NE, USA) were added and incubated for $1 \mathrm{~h}$ at room temperature in a dark place. Membranes were scanned using the Odyssey ${ }^{\circledR}$ CLx Imaging system (LI-COR Biosciences) and the protein expression was quantified using Image Studio $^{\text {TM }}$ Software (LI-COR Biosciences).

Radioimmunoassay (RIA) for testosterone analysis. Serum was separated from blood collected from male offspring by centrifugation at $3000 \mathrm{x} g$ for $10 \mathrm{~min}$ at room temperature and stored at $-80^{\circ} \mathrm{C}$ until required for the testosterone assay. Fetal testes were rinsed with $0.01 \mathrm{M}$ PBS and homogenized in $150 \mu \mathrm{l}$ $0.01 \mathrm{M}$ PBS. The homogenate was centrifuged for $10 \mathrm{~min}$ at $5000 \times g$ at $4^{\circ} \mathrm{C}$, and the supernatant was collected and stored at $-80^{\circ} \mathrm{C}$ until required. ${ }^{125} \mathrm{I}$-based RIA kits were purchased from the Beijing North Institute of Biological Technology (Beijing, China). Testosterone levels were measured according to the manufacturer's protocol, and expressed as $\mathrm{ng} / \mathrm{ml}$.

Histopathology and immunohistochemistry. The testes were immersed in $4 \%$ paraformaldehyde for fixation, dehydrated via a graded series of ethanol washes followed by xylene, and embedded in paraffin. Paraffin-embedded tissues were serially sectioned (5- $\mu \mathrm{m}$ thick), mounted onto glass slides coated with poly-L-lysine, deparaffinized with xylene and rehydrated with graded ethanol. At least two non-serial sections were stained with hematoxylin and eosin $(\mathrm{H} \& \mathrm{E})$ using standard procedures for morphological analyses. For histological evaluation of apoptosis, DNA fragmentation was examined using 
Table I. Sequences of the specific oligonucleotide primers used for polymerase chain reaction amplification.

\begin{tabular}{|c|c|c|c|}
\hline Target gene & Genbank no. & $\begin{array}{c}\text { Product } \\
\text { length (bp) }\end{array}$ & Primer sequence (5'-3') \\
\hline Scavenger receptor class B & NM_031541 & 134 & $\begin{array}{l}\text { F:ctcctgactttctccgtctttc } \\
\text { R:caggatctggaactgcttgt }\end{array}$ \\
\hline Steroidogenic acute regulatory protein & NM_031558 & 125 & $\begin{array}{l}\text { F:tcaactggaagcaacactctac } \\
\text { R:cctgctggctttccttctt }\end{array}$ \\
\hline Cytochrome P-450 side chain cleavage & NM_017286 & 156 & $\begin{array}{l}\text { F:ctggtgacaatggttggataaac } \\
\text { R:ccttagggtccaggatgtaaac }\end{array}$ \\
\hline 3ß-hydroxysteroid dehydrogenase & M38178 & 141 & $\begin{array}{l}\text { F:tgttggtgcaggagaaagaa } \\
\text { R:ggtactgggcatccagaatatc }\end{array}$ \\
\hline Cytochrome P-450, family 17 & NM_012753 & 170 & $\begin{array}{l}\text { F:gcctttgcagatgctggta } \\
\text { R:ggcgtggacaggtctat }\end{array}$ \\
\hline $17 \beta$-hydroxysteroid dehydrogenase & NM_012851 & 180 & $\begin{array}{l}\text { F:aggctttaccagggtctttc } \\
\text { R:cagtggtcctctcaatctcttc }\end{array}$ \\
\hline Insulin-like factor 3 & NM_053680 & 130 & $\begin{array}{l}\text { F:gcacccagcaagaccttt } \\
\text { R:tagggatcctccaaggcaat }\end{array}$ \\
\hline GAPDH & NM_017008 & 155 & $\begin{array}{l}\text { F:actcccattcttccacctttg } \\
\text { R:gtccagggtttcttactccttg }\end{array}$ \\
\hline
\end{tabular}

F, forward; R, reverse.

the Terminal Deoxynucleotidyl Transferase dUTP Nick-End Labeling assay (TUNEL) Detection kit (cat. no. 11684817910; Roche Diagnostics, Basel, Switzerland) according to the manufacturer's protocol. Slides were incubated with $20 \mu \mathrm{g} / \mathrm{ml}$ proteinase $\mathrm{K}$ for $15 \mathrm{~min}$ at room temperature and washed with PBS three times. The slides were subsequently incubated with TUNEL reaction buffer for $60 \mathrm{~min}$ at $37^{\circ} \mathrm{C}$ in a humidified atmosphere in the dark. Following a further wash with PBS, the slides were incubated with an anti-converter-peroxidase secondary antibody, which was part of the TUNEL kit (Roche Diagnostics) for $30 \mathrm{~min}$ at $37^{\circ} \mathrm{C}$, and the signal was visualized with diaminobenzidine (DAB; OriGene Technologies, Inc., Beijing, China). The number of positive cells was calculated for analysis under a light microscope.

Testicular Leydig cells were identified in 5- $\mu \mathrm{m}$ thick paraffin sections by immunohistochemistry for $3 \beta$-HSD. Antigen retrieval was performed by microwave oven heating for $5 \mathrm{~min}$ in $0.01 \mathrm{M}$ citrate buffer ( $\mathrm{pH} \mathrm{6.0)}$. The slides were incubated for $10 \mathrm{~min}$ in $3 \%(\mathrm{v} / \mathrm{v})$ hydrogen peroxide in PBS to block endogenous peroxidase activity and subsequently washed with PBS. Following blocking with normal goat serum (Beijing Zhongshan Golden Bridge Biotechnology; OriGene Technologies, Inc., Rockville, MD, USA) diluted 1:5 in PBS containing 5\% BSA, the slides were incubated overnight at $4{ }^{\circ} \mathrm{C}$ with a rabbit polyclonal anti-3 $\beta$-HSD antibody (diluted 1:100 in antibody dilutions liquid (cat. no. ZLI-9028; Beijing Zhongshan Golden Bridge Biotechnology; OriGene Technologies, Inc.). Following this, the slides were washed with PBS and incubated with the horseradish peroxidase-conjugated goat anti-rabbit IgG secondary antibody (provided at working dilution; cat. no. PV-6001; Beijing Zhongshan Golden Bridge Biotechnology; OriGene Technologies, Inc.) at $37^{\circ} \mathrm{C}$ for $30 \mathrm{~min}$. The slides were subsequently stained using a DAB kit, washed with water, then stained with hematoxylin, dehydrated using sequential concentrations ethanol, being washed for $2 \mathrm{~min}$ in each starting with $80 \%$, followed by $95 \%$ and finishing with $100 \%$ ethanol twice, and placed under cover slips. The density of $3 \beta$-HSD-immunoreactivity was detected as described previously (23). Briefly, photomicrographic digital images were obtained from $3 \beta$-HSD-immunostained sections of the fetal testes, and regions of these photomicrographs were analyzed to measure the density of $3 \beta$-HSD immunoreactivity in the interstitial region of the testes. The surface area of the total interstitial region and the $3 \beta$-HSD-immunoreactive area were subsequently measured using ImageJ software version 1.46 (National Institute of Health). Areas darker than 100 of 256 pixels were determined to be $3 \beta$-HSD-immunoreactive. The positive $3 \beta$-HSD-immunoreactive area was normalized by dividing by the total area of the interstitial region of interest, and was expressed as the $3 \beta$-HSD-immunoreactive area/ $1-\mathrm{mm}^{2}$ area of the interstitial region of the fetal testes.

Statistical analysis. Statistical analysis was performed using SPSS software version 12.0 (SPSS, Inc., Chicago, IL, USA). The data were examined for normal distribution and homogeneity of variance. Normally distributed and variance homogeneous data were analyzed by one-way analysis of variance. Dunnett's post hoc test was used to compare the values from acrolein-treated animals with the control group. Data are presented as the mean \pm standard deviation. $\mathrm{P}<0.05$ was considered to indicate a statistically significant difference.

\section{Results}

Effects of maternal acrolein exposure on pregnant rats and fetus development. To investigate the effects of maternal acrolein exposure during pregnancy on maternal weight gain and 

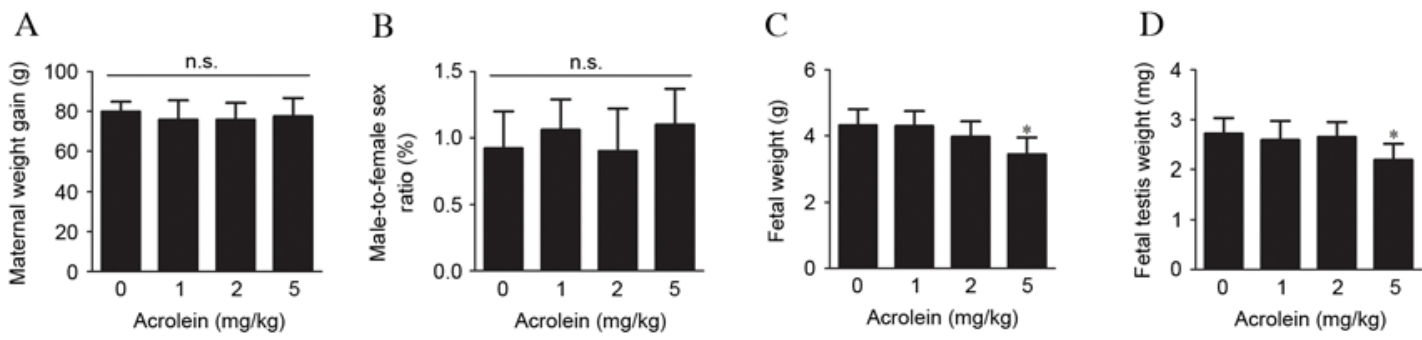

Figure 1. Effects of maternal acrolein exposure on offspring sex and male fetuses. (A) Maternal weight gain, (B) male to female ratio of offspring, and the (C) body and (D) testicular weight of male fetuses. Data are presented as the mean \pm standard deviation $(\mathrm{n}=32-39)$. ${ }^{*} \mathrm{P}<0.01 \mathrm{vs} .0 \mathrm{mg} / \mathrm{kg}$ acrolein. $\mathrm{n} . \mathrm{s}$., non-significant.

A

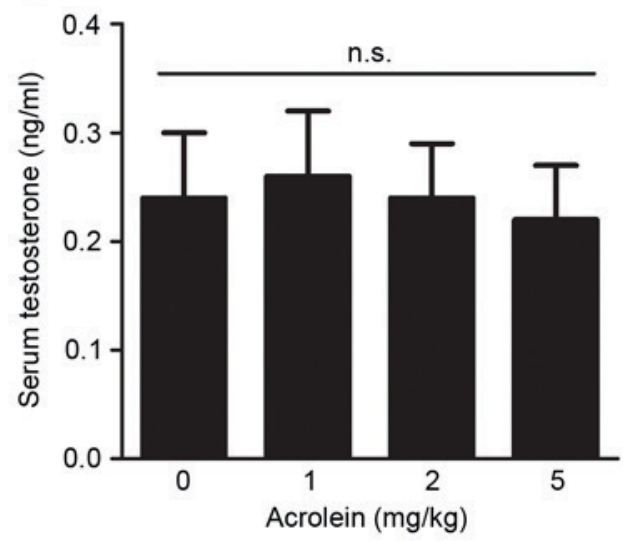

B

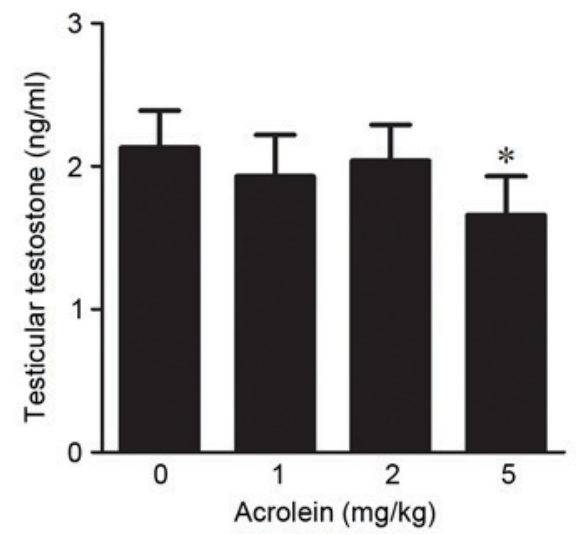

Figure 2. Effects of maternal acrolein exposure on testosterone production. (A) Serum and (B) testicular testosterone concentration. Data are presented as the mean \pm standard deviation $(\mathrm{n}=12-15) .{ }^{*} \mathrm{P}<0.01 \mathrm{vs} .0 \mathrm{mg} / \mathrm{kg}$ acrolein. n.s., non-significant.

fetus development, pregnant rats were injected i.p. with 0,1 , 2 or $5 \mathrm{mg} / \mathrm{kg}$ acrolein daily from GD 14-20. No significant differences in body weight gain in the pregnant rats were observed between the acrolein-treated and control groups (Fig. 1A). Although no significant differences were observed in the male-to-female sex ratio (Fig. 1B), the weight of the pups was markedly reduced when pregnant rats received acrolein at $5 \mathrm{mg} / \mathrm{kg}$ compared with the control $(\mathrm{P}=0.003$, Fig. 1C). However, no significant effect on fetal weight was observed in groups administered with 1 or $2 \mathrm{mg} / \mathrm{kg}$ acrolein. In addition, the weight of the fetal testes in the group treated with $5 \mathrm{mg} / \mathrm{kg}$ acrolein was reduced compared with the control group $(\mathrm{P}=0.001)$, while no significant alterations were observed in the other groups (Fig. 1D).

Effects of maternal acrolein exposure on testosterone production in fetal rats. The effects of maternal acrolein exposure during pregnancy on testosterone production in the serum and testes were analyzed. As presented in Fig. 2A, no significant effects of acrolein on serum testosterone were observed in fetal rats. However, compared with the control, the intratesticular testosterone concentration was markedly reduced following treatment with $5 \mathrm{mg} / \mathrm{kg}$ acrolein $(\mathrm{P}<0.001$, Fig. 2B). Although testosterone in the groups treated with 1 and $2 \mathrm{mg} / \mathrm{kg}$ acrolein decreased compared with the control group, no statistically significant differences were observed.
Effects of maternal acrolein exposure on the expression levels of steroidogenic genes and insulin-like factor 3 (Insl3). A panel of genetic markers associated with testosterone production was used to assess the steroidogenic function in the fetal testes following prenatal exposure to acrolein. No significant differences were observed in the mRNA expression levels of the scavenger receptor class B member 1 (SR-B1; Fig. 3A). However, there was a slight increase in $17 \beta-H S D$ mRNA expression levels in the $1 \mathrm{mg} / \mathrm{kg}$ group $(\mathrm{P}=0.032$, Fig. $3 \mathrm{~B})$. No significant differences in mRNA expression levels were observed in the other steroidogenic enzymes assessed, cholesterol side-chain cleavage enzyme (P450scc; Fig. 3C) and steroid 17 alpha-hydroxylase/17,20 lyase (P450c17; Fig. 3D). The mRNA expression levels of $3 \beta$-HSD were only reduced in the $5 \mathrm{mg} / \mathrm{kg}$ group $(\mathrm{P}=0.020$, Fig. $3 \mathrm{E})$. These alterations were consistent with reduced intratesticular testosterone levels. No significant alterations in the mRNA expression levels of Insl-3, a critical gene involved in testicular descent, were observed in any of the groups treated with acrolein, compared with the control group (Fig. 3F). The mRNA expression levels of the cholesterol transporter StAR in fetal testes were reduced following exposure to 2 and $5 \mathrm{mg} / \mathrm{kg}$ acrolein $(\mathrm{P}=0.009$ and $\mathrm{P}=0.038$, respectively), compared with the control group, while no significant differences were observed in the $1 \mathrm{mg} / \mathrm{kg}$ group (Fig. 3G). Alterations in protein expression levels of StAR were in accordance with mRNA expression levels (Fig. 3H). 
A

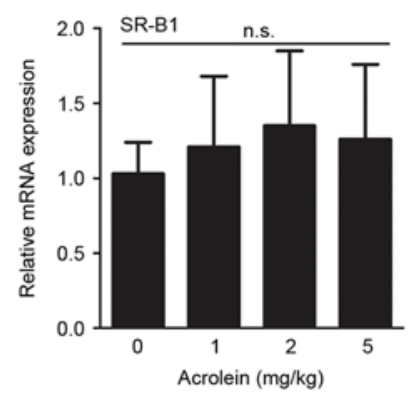

E

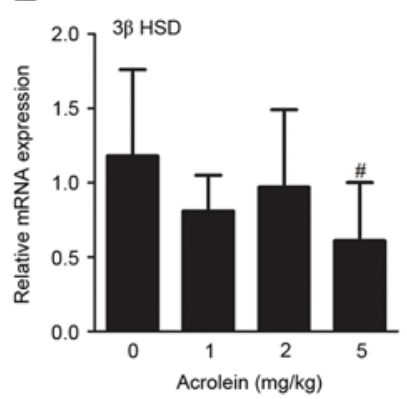

B

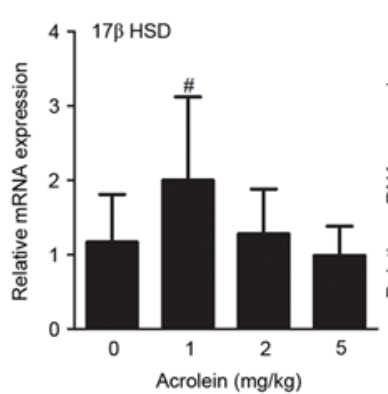

F

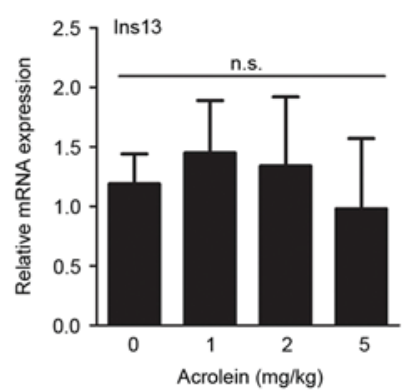

C

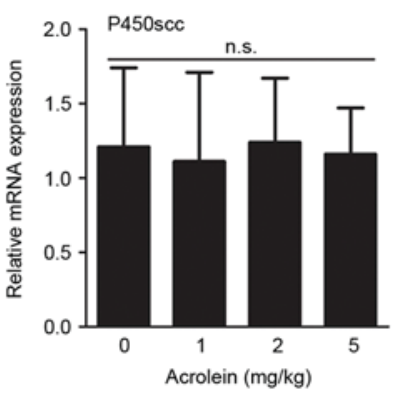

G

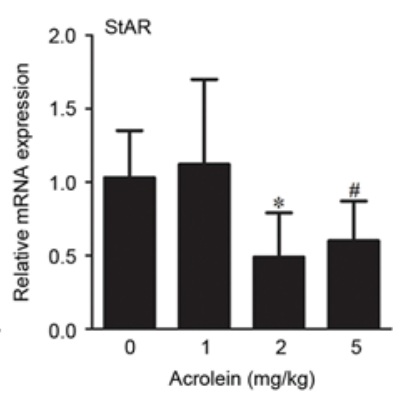

D

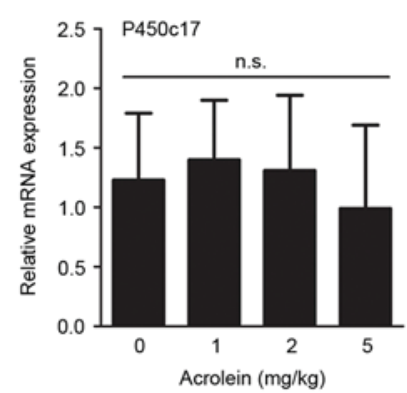

$\mathrm{H}$

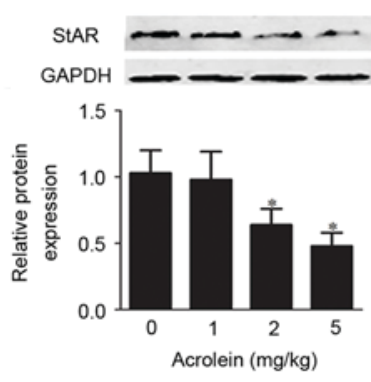

Figure 3. Gene expression analysis. Reverse transcription-quantitative polymerase chain reaction analysis of the expression of (A) SR-B1, (B) 17 $\beta$ HSD, (C) P450scc, (D) P450c17, (E) 33 HSD, (F) Ins13 and (G) StAR. (H) Representative western blot images and analysis of StAR protein expression levels in fetal testes following maternal acrolein exposure. Data are presented as the mean \pm standard deviation $(\mathrm{n}=6-8)$. ${ }^{*} \mathrm{P}<0.05$ and ${ }^{*} \mathrm{P}<0.01 \mathrm{vs} .0 \mathrm{mg} / \mathrm{kg}$ acrolein. SR-B1, scavenger receptor class B;StAR, steroidogenic acute regulatory protein; P450scc, cholesterol side-chain cleavage enzyme; P450c17, steroid 17 alpha-hydroxylase/17,20 lyase; HSD, hydroxysteroid dehydrogenase; Ins13, insulin-like factor 13; n.s., non-significant.
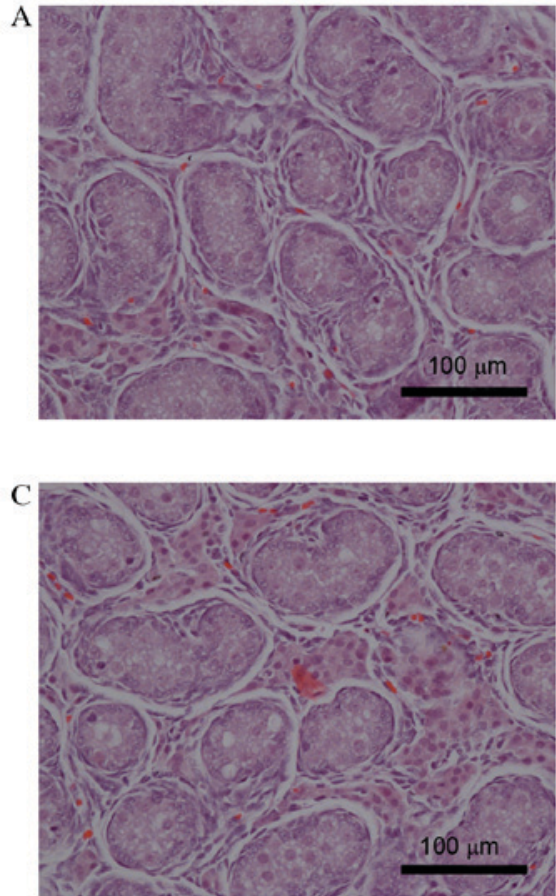
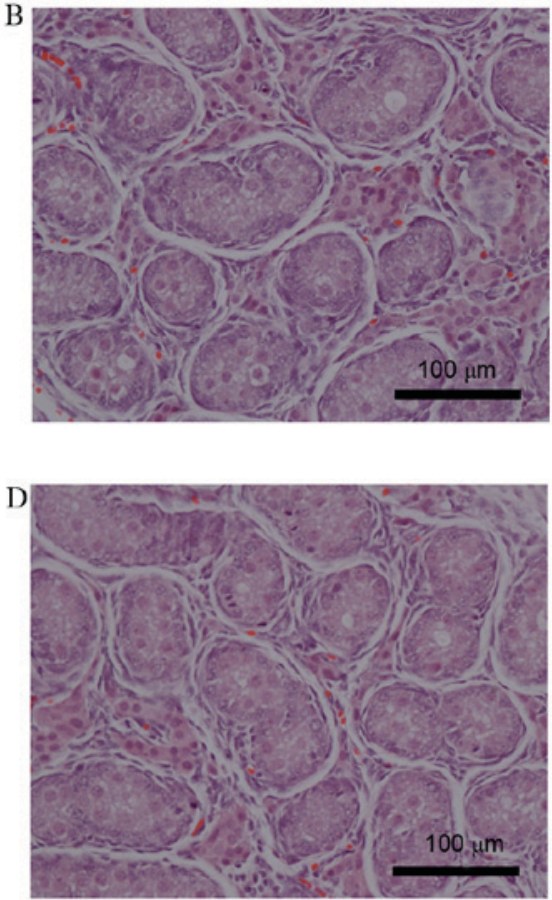

Figure 4. Effects of maternal acrolein exposure on testicular histology. Representative hematoxylin and eosin stained sections from fetal testes following exposure to (A) 0 , (B) 1 , (C) 2 and (D) $5 \mathrm{mg} / \mathrm{kg}$ acrolein. Scale bar= $100 \mu \mathrm{m}$.

Effects of maternal acrolein exposure on fetal testes histopathology. The effects of maternal acrolein exposure during pregnancy on fetal testes histology were determined by
H\&E staining. As presented in Fig. 4, no abnormal morphology was observed in the fetal testes of the acrolein-treated rats compared with the control group. The distribution of Leydig 

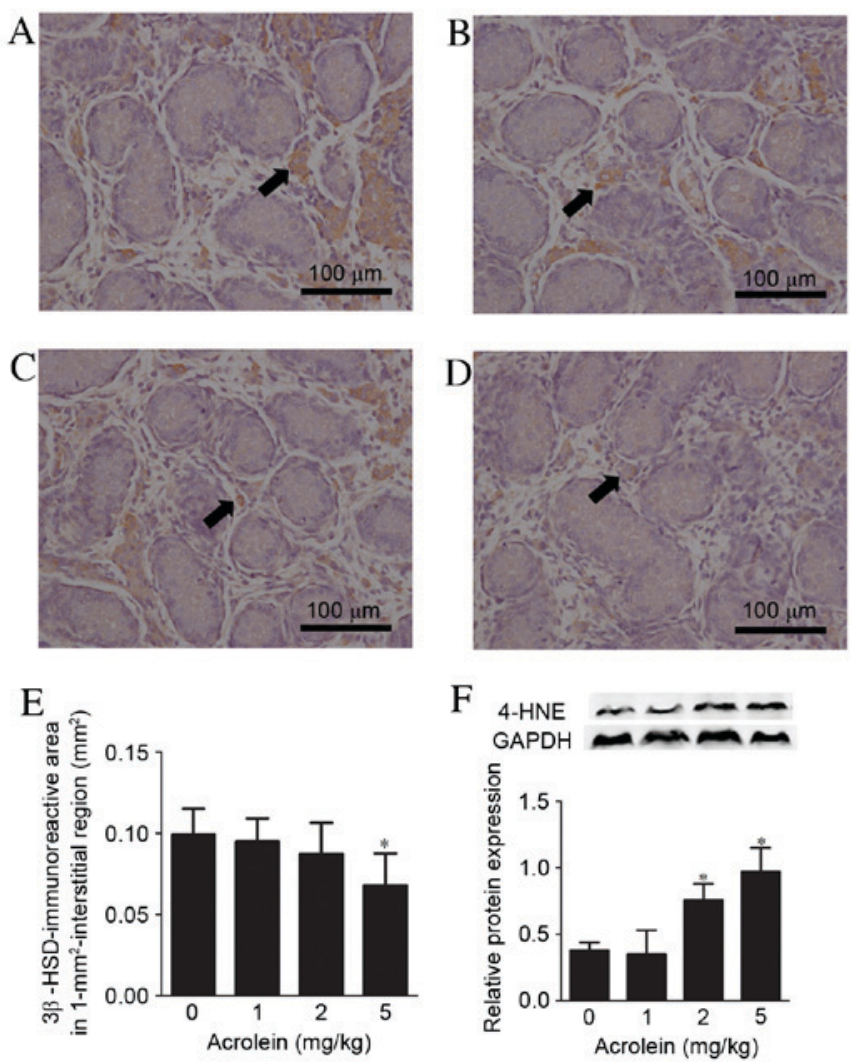

Figure 5. Effects of maternal acrolein exposure on $3 \beta$-HSD immunoreactivity in the interstitial region and the protein expression levels of 4-HNE in feta testes. Representative images of $3 \beta$-HSD stained sections from fetal testes following exposure to (A) 0 , (B) 1 , (C) 2 and (D) $5 \mathrm{mg} / \mathrm{kg}$ acrolein. Scale bar $=100 \mu \mathrm{m}$. Arrows indicate $3 \beta$-HSD-positive staining. (E) Quantification of the $3 \beta$-HSD immunoreactive area in each group. $(\mathrm{F})$ Representative western blot images and analysis of the protein expression levels of 4-HNE in fetal testes following maternal exposure to acrolein. Data are presented as the mean \pm standard deviation $(\mathrm{n}=6-8) .{ }^{*} \mathrm{P}<0.01 \mathrm{vs} .0 \mathrm{mg} / \mathrm{kg}$ acrolein. $3 \beta-\mathrm{HSD}$ $3 \beta$-hydroxysteroid dehydrogenase; 4-HNE, 4-hydroxynonenal.

cells was identified by immunohistochemical staining for the Leydig cell type-specific marker, $3 \beta$-HSD (Fig. 5A-D). The $3 \beta$-HSD immunoreactive area in the interstitial region of the fetal testes was reduced following exposure to $5 \mathrm{mg} / \mathrm{kg}$ acrolein during pregnancy $(\mathrm{P}=0.004)$, whereas the immunoreactive areas in the 1 and $2 \mathrm{mg} / \mathrm{kg}$ groups were unaltered compared with controls (Fig. 5E). ATUNEL assay revealed that there were no significant differences in cell death in fetal testes between the acrolein exposure and control groups (data not shown). The protein expression levels of 4-HNE, an indicator of oxidative stress, were subsequently examined in fetal testes. As presented in Fig. 5F, the protein expression levels of 4-HNE increased following fetal exposure to acrolein in a dose-dependent manner $(\mathrm{P}<0.001)$.

\section{Discussion}

Acrolein has been reported to have diverse toxic effects in numerous organs,includingthe reproductivesystem(11). Various studies have demonstrated that acrolein exposure impairs male germ cells, sertoli cells and spermatogenesis $(14,24,25)$. In the present study, the dose-associated effects of acrolein exposure during pregnancy on fetal testosterone production and gene expression were investigated. The results demonstrated that the weight of pups and fetal testes were significantly decreased when prenatally exposed to high doses of acrolein $(5 \mathrm{mg} / \mathrm{kg})$. Furthermore, maternal acrolein exposure during pregnancy resulted in a reduction of intratesticular testosterone production and the expression of steroidogenic genes, including StAR and 3 $\beta$-HSD, and impaired function of Leydig cells. These results indicated that high doses of acrolein exposure in utero impair steroidogenic capacity during the fetal period.

Testosterone is primarily synthesized by testicular Leydig cells. Fetal Leydig cells are a distinct population that exhibit a specific origin, structure and capacity for testosterone production, and are regulated by hormones and growth factors $(26,27)$. Leydig cells begin to appear in the interstitial tissue of the developing testes following the formation of testicular cords, reach peak numbers around birth and gradually disappear following postnatal day 7 (28). Previous studies have demonstrated that various environmental toxicants, including phthalate and perfluorooctane sulfonate, may cause impairment of rat fetal Leydig cells and reduction of testosterone production $(29,30)$. Although no direct evidence has indicated that acrolein impairs steroidogenic capacity, males treated with high doses of $\mathrm{CP}$, the precursor of acrolein, for sarcoma during childhood had abnormally elevated gonadotrophin-releasing hormone-stimulated luteinizing hormone levels, suggesting a degree of Leydig cell insufficiency (16). In the present study, a high dose of acrolein $(5 \mathrm{mg} / \mathrm{kg})$ significantly decreased fetal testicular testosterone concentration following prenatal exposure, whereas fetal testosterone was unaffected following treatment with low doses of acrolein ( 1 and $2 \mathrm{mg} / \mathrm{kg}$ ). Exposure to pollutants, including toluene, during pregnancy is associated with an abnormal $3 \beta-\mathrm{HSD}$ immunoreactive area in fetal testes (23); the present study additionally demonstrated that prenatal acrolein treatment had similar effects. Furthermore, high doses of acrolein exposure $(5 \mathrm{mg} / \mathrm{kg})$ during pregnancy were revealed to lead to weight reduction in the male fetus and fetal testes.

The synthesis of testosterone in Leydig cells requires a series of steroidogenic enzymes, including SR-B1, StAR, P450scc, 3 $\beta$-HSD, P450c17 and 17 $\beta$-HSD (31). The mechanisms underlying reduced fetal testosterone levels following exposure to acrolein were investigated by assessing the mRNA expression levels of these steroidogenic enzymes. SR-B1 is responsible for the transport of high-density lipoprotein (HDL) cholesteryl esters into the cell; the present study demonstrated that the expression levels of SR-B1 were unaffected following exposure to acrolein. StAR is important for the delivery of cholesterol from the outer to the inner mitochondrial membrane in fetal testes (32). In the present study, the mRNA and protein expression levels of this cholesterol transport molecule were markedly decreased following treatment with 2 and $5 \mathrm{mg} / \mathrm{kg}$ acrolein. Additionally, previous studies have demonstrated that acrolein impairs cholesterol transport by modification of apolipoprotein A-I and HDL, and that cholesterol is essential for testosterone biosynthesis (33). P450scc is involved in catalyzing the conversion of cholesterol to pregnenolone, which is subsequently transported to the smooth endoplasmic reticulum in the cytoplasm, where $3 \beta$-HSD converts it to progesterone, following conversion to 
testosterone by P450c17 and 17 $\beta$-HSD (34). In the present study, the mRNA expression levels of $3 \beta-H S D$ were reduced by exposure to $5 \mathrm{mg} / \mathrm{kg}$ acrolein, while the mRNA expression levels of P450scc, P450c17 and 17 $\beta$-HSD were not significantly altered, with the exception of a slight increase in $17 \beta$-HSD in the $2 \mathrm{mg} / \mathrm{kg}$ group. These results suggested that high doses of acrolein exposure impairs the steroidogenic capacity in testosterone synthesis by reducing StAR and $3 \beta$-HSD expression levels in fetal testes, and that the inhibitory effect on steroidogenesis appears to result from selective alterations of gene expression.

Insl3 is another important factor secreted by fetal Leydig cells, and specifically binds to the leucine-rich repeat-containing $G$ protein-coupled receptor 8 in the gubernaculums to induce scrotal descent of the testes (35). Therefore, interference with the expression of Insl3 may lead to cryptorchidism. The present data suggested that prenatal acrolein exposure does not affect the mRNA expression levels of Ins13. In addition, fetal testes were not histologically damaged following maternal acrolein exposure. Previous studies have demonstrated that acrolein impairs the sertoli cytoskeleton and induces germ cell apoptosis by induction of oxidative stress in vitro $(24,25)$, and that it negatively regulates meiosis in a yeast gametogenesis model by inhibiting premeiotic DNA synthesis (14). The present results revealed that prenatal acrolein in vivo does not lead to an evident morphological alteration, which is consistent with a study that demonstrated that the mating pattern and fertility of rats were unaffected following acrolein treatment (36). Additionally, Kuwada et al (37) revealed that neonatal endocrine disruptors exposure decreases weight and steroidogenesis of juvenile testes, whereas spermatogenesis was restored during puberty. However, the effects of prenatal acrolein exposure on the function of sertoli and germ cells remain to be fully elucidated. Taken together, these studies indicated that maternal acrolein exposure during pregnancy does not cause a distinct pathological impairment in fetal testes, with the exception of reduced steroidogenic capacity at a dose of $5 \mathrm{mg} / \mathrm{kg}$ acrolein.

Exposure to environmental pollutants often generates excessive levels of reactive oxygen species (ROS) and induces oxidative stress responses in cells (38). ROS, including oxygen radicals, have been demonstrated to disrupt the balance of the endocrine system and inhibit testicular steroidogenesis $(39,40)$. Acrolein, an unsaturated $\alpha, \beta$-aldehyde, reacts with and depletes cell antioxidants, including glutathione, and affects the cellular redox balance (25). 4-HNE is an aldehydic product of lipid peroxidation and has been considered an indicator of oxidative stress-induced cell death (41). Thus, the protein expression levels of 4-HNE in fetal testes were examined following maternal acrolein exposure. It was demonstrated that the protein expression levels of 4-HNE were increased in testes following fetal exposure to acrolein in a dose-dependent manner, indicating that acrolein-induced oxidative stress damage may be implicated in the etiology of fetal testicular pathological alterations.

In conclusion, the results of the present study indicated that prenatal exposure to high doses of acrolein significantly reduced fetal and testes weight and most notably, testicular testosterone production capacity. The abnormal expression of StAR and 3 $\beta$-HSD, and oxidative stress damage, may contribute to the impairment of steroidogenesis. Consequently, these alterations may result in the maldevelopment of the testes and affect masculinization.

\section{Acknowledgements}

The present study was supported by the Peking University 985 Clinical Hospital Cooperation Program (grant no. B67463). The authors would like to thank all staff of the Key Laboratory of Assisted Reproduction (Peking University Third Hospital, Beijing, China) for their assistance.

\section{References}

1. Skakkebaek NE, Rajpert-De Meyts E and Main KM: Testicular dysgenesis syndrome: An increasingly common developmental disorder with environmental aspects. Hum Reprod 16: 972-978, 2001.

2. Schnack TH, Poulsen G, Myrup C, Wohlfahrt J and Melbye M: Familial coaggregation of cryptorchidism, hypospadias, and testicular germ cell cancer: A nationwide cohort study. J Natl Cancer Inst 102: 187-192, 2010.

3. Sharpe RM and Skakkebaek NE: Testicular dysgenesis syndrome: Mechanistic insights and potential new downstream effects. Fertil Steril 89 (2 Suppl): e33-e38, 2008.

4. Macleod DJ, Sharpe RM, Welsh M, Fisken M, Scott HM, Hutchison GR, Drake AJ and van den Driesche S: Androgen action in the masculinization programming window and development of male reproductive organs. Int J Androl 33: 279-287, 2010.

5. Liu D, Shen L, Tao Y, Kuang Y, Cai L, Wang D, He M, Tong X, Zhou S, Sun J, et al: Alterations in gene expression during sexual differentiation in androgen receptor knockout mice induced by environmental endocrine disruptors. Int J Mol Med 35: 399-404, 2015.

6. Araki A, Mitsui T, Miyashita C, Nakajima T, Naito H, Ito S, Sasaki S, Cho K, Ikeno T, Nonomura K and Kishi R: Association between maternal exposure to di (2-ethylhexyl) phthalate and reproductive hormone levels in fetal blood: The Hokkaido study on environment and children's health. PLoS One 9: e109039, 2014.

7. Wilson VS, Lambright CR, Furr JR, Howdeshell KL and Earl Gray L Jr: The herbicide linuron reduces testosterone production from the fetal rat testis during both in utero and in vitro exposures. Toxicol Lett 186: 73-77, 2009.

8. Stevens JF and Maier CS: Acrolein: Sources, metabolism, and biomolecular interactions relevant to human health and disease. Mol Nutr Food Res 52: 7-25, 2008

9. Cahill TM: Ambient acrolein concentrations in coastal, remote, and urban regions in California. Environ Sci Technol 48: 8507-8513, 2014.

10. Logue JM, Price PN, Sherman MH and Singer BC: A method to estimate the chronic health impact of air pollutants in U.S. residences. Environ Health Perspect 120: 216-222, 2012.

11. Moghe A, Ghare S, Lamoreau B, Mohammad M, Barve S, McClain C and Joshi-Barve S: Molecular mechanisms of acrolein toxicity: Relevance to human disease. Toxicol Sci 143: 242-255, 2015.

12. DeJarnett N, Conklin DJ, Riggs DW, Myers JA, O'Toole TE, Hamzeh I, Wagner S, Chugh A, Ramos KS, Srivastava S, et al: Acrolein exposure is associated with increased cardiovascular disease risk. J Am Heart Assoc 3: pii: e000934, 2014.

13. Lovell MA, Xie C and Markesbery WR: Acrolein is increased in Alzheimer's disease brain and is toxic to primary hippocampal cultures. Neurobiol Aging 22: 187-194, 2001.

14. Golla U, Bandi G and Tomar RS: Molecular cytotoxicity mechanisms of allyl alcohol (acrolein) in budding yeast. Chem Res Toxicol 28: 1246-1264, 2015.

15. Slott VL and Hales BF: The embryolethality and teratogenicity of acrolein in cultured rat embryos. Teratology 34: 155-163, 1986.

16. Kenney LB, Laufer MR, Grant FD, Grier H and Diller L: High risk of infertility and long term gonadal damage in males treated with high dose cyclophosphamide for sarcoma during childhood. Cancer 91: 613-621, 2001. 
17. Westlind A, Malmebo S, Johansson I, Otter C, Andersson TB, Ingelman-Sundberg $\mathrm{M}$ and Oscarson $\mathrm{M}$ : Cloning and tissue distribution of a novel human cytochrome p450 of the CYP3A subfamily, CYP3A43. Biochem Biophys Res Commun 281: $1349-1355,2001$.

18. Ekhart C, Doodeman VD, Rodenhuis S, Smits PH, Beijnen JH and Huitema AD: Influence of polymorphisms of drug metabolizing enzymes (CYP2B6, CYP2C9, CYP2C19, CYP3A4, CYP3A5, GSTA1, GSTP1, ALDH1A1 and ALDH3A1) on the pharmacokinetics of cyclophosphamide and 4-hydroxycyclophosphamide. Pharmacogenet Genomics 18: 515-523, 2008.

19. Ji YL, Wang H, Liu P, Zhao XF, Zhang Y, Wang Q, Zhang H, Zhang C, Duan ZH, Meng C and Xu DX: Effects of maternal cadmium exposure during late pregnant period on testicular steroidogenesis in male offspring. Toxicol Lett 205: 69-78, 2011.

20. Auerbach SS, Mahler J, Travlos GS and Irwin RD: A comparative 90-day toxicity study of allyl acetate, allyl alcohol and acrolein. Toxicology 253: 79-88, 2008

21. Rashedinia M, Lari P, Abnous K and Hosseinzadeh H: Proteomic analysis of rat cerebral cortex following subchronic acrolein toxicity. Toxicol Appl Pharmacol 272: 199-207, 2013.

22. Livak KJ and Schmittgen TD: Analysis of relative gene expression data using real-time quantitative PCR and the 2(-Delta Delta C(T)) method. Methods 25: 402-408, 2001.

23. Tsukahara S, Nakajima D, Kuroda Y, Hojo R, Kageyama S and Fujimaki H: Effects of maternal toluene exposure on testosterone levels in fetal rats. Toxicol Lett 185: 79-84, 2009.

24. Liu F, Li XL, Lin T, He DW, Wei GH, Liu JH and Li LS: The cyclophosphamide metabolite, acrolein, induces cytoskeletal changes and oxidative stress in Sertoli cells. Mol Biol Rep 39: 493-500, 2012

25. He X, Song W, Liu C, Chen S and Hua J: Rapamycin inhibits acrolein-induced apoptosis by alleviating ROS-driven mitochondrial dysfunction in male germ cells. Cell Prolif 47: 161-171, 2014.

26. Griswold SL and Behringer RR: Fetal Leydig cell origin and development. Sex Dev 3: 1-15, 2009.

27. O'Shaughnessy PJ, Baker PJ and Johnston H: The foetal Leydig cell-differentiation, function and regulation. Int J Androl 29: 90-108, 2006.

28. Habert R, Lejeune H and Saez JM: Origin, differentiation and regulation of fetal and adult Leydig cells. Mol Cell Endocrinol 179: 47-74, 2001.

29. Zhao B, Li L, Liu J, Li H, Zhang C1, Han P, Zhang Y, Yuan X, Ge RS and Chu Y: Exposure to perfluorooctane sulfonate in utero reduces testosterone production in rat fetal Leydig cells. PLoS One 9: e78888, 2014.
30. Lin H, Ge RS, Chen GR, Hu GX, Dong L, Lian QQ, Hardy DO, Sottas CM, Li XK and Hardy MP: Involvement of testicular growth factors in fetal Leydig cell aggregation after exposure to phthalate in utero. Proc Natl Acad Sci USA 105: 7218-7222, 2008.

31. Payne AH and Hales DB: Overview of steroidogenic enzymes in the pathway from cholesterol to active steroid hormones. Endocr Rev 25: 947-970, 2004.

32. Tyczewska M, Rucinski M, Ziolkowska A, Trejter M, Szyszka M and Malendowicz LK: Expression of selected genes involved in steroidogenesis in the course of enucleation-induced rat adrenal regeneration. Int J Mol Med 33: 613-623, 2014.

33. Chadwick AC, Holme RL, Chen Y, Thomas MJ, Sorci-Thomas MG, Silverstein RL, Pritchard KA Jr and Sahoo D: Acrolein impairs the cholesterol transport functions of high density lipoproteins. PLoS One 10: e0123138, 2015.

34. Luu-The V: Assessment of steroidogenesis and steroidogenic enzyme functions. J Steroid Biochem Mol Biol 137: 176-182, 2013.

35. Ivell $\mathrm{R}$ and Bathgate $\mathrm{RA}$ : Reproductive biology of the relaxin-like factor (RLF/INSL3). Biol Reprod 67: 699-705, 2002.

36. Parent RA, Caravello HE and Hoberman AM: Reproductive study of acrolein on two generations of rats. Fundam Appl Toxicol 19: 228-237, 1992.

37. Kuwada M, Kawashima R, Nakamura K, Kojima H, Hasumi H, Maki J and Sugano S: Neonatal exposure to endocrine disruptors suppresses juvenile testis weight and steroidogenesis but spermatogenesis is considerably restored during puberty. Biochem Biophys Res Commun 295: 193-197, 2002.

38. Monroe RK and Halvorsen SW: Environmental toxicants inhibit neuronal Jak tyrosine kinase by mitochondrial disruption. Neurotoxicology 30: 589-598, 2009.

39. Shi Z, Feng Y, Wang J, Zhang H, Ding L and Dai J: Perfluorododecanoic acid-induced steroidogenic inhibition is associated with steroidogenic acute regulatory protein and reactive oxygen species in cAMP-stimulated Leydig cells. Toxicol Sci 114: 285-294, 2010.

40. Zhou L, Beattie MC, Lin CY, Liu J, Traore K, Papadopoulos V, Zirkin BR and Chen H: Oxidative stress and phthalate-induced down-regulation of steroidogenesis in MA-10 Leydig cells. Reprod Toxicol 42: 95-101, 2013.

41. Ayala A, Muñoz MF and Argüelles S: Lipid peroxidation: Production, metabolism, and signaling mechanisms of malondialdehyde and 4-hydroxy-2-nonenal. Oxid Med Cell Longev 2014: $360438,2014$. 